DE HOMERO A LAIDLAW

\section{La digitalización}

recupera la

participación en

\section{la obra narrativa}

\section{Beatriz Legerén Lago}

Doctora en Comunicación Audiovisual

\begin{abstract}
Facultad de Ciencias Sociales y de la Comunicación. Campus A Xunqueira s/n 36005 Pontevedra (España) - Email: blegeren@uvigo.es
\end{abstract}

\section{Resumen}

La digitalización nos permite recuperar la esencia de la comunicación: la participación en la obra.

Aunque la narrativa no lineal pueda parecer innovadora y muy reciente, es la forma más antigua de narrar. La narrativa lineal se impone con la aparición de la escritura y el teatro (sobre todo de la escritura de las obras de teatro).La tradición narrativa de los bardos, presentes con uno u otro nombre en todas las culturas, era una tradición narrativa no lineal. Un ejemplo perfecto lo tenemos en el poema épico La Odisea, atribuido a Homero si algún día existió ese personaje.

Es con la llegada del siglo XX cuando se comienza a experimentar más con este tipo de narrativa dentro del arte, haciendo cada vez más partícipe al espectador del curso de la narración.
Palabras clave

Interactividad, digitalización,

narración, literatura,

exploración, autor, lector

Key Words

Interactivity, digitalization, narrative, literature,

exploration, author, reader

\section{Abstract}

Digitization enables us to rediscover the essence of communication: participation in the

story. Although non-linear narrative may seem very recent and innovative, it is in fact the

oldest form of storytelling.

Linear narrative only became the norm when plays began to be

written down. The narrative tradition of bards, which have been present with one name or another in all cultures, was a non-linear narrative tradition. A perfect example of this is "The

Odyssey", the epic poem attributed to Homer. Experimentation on non-linear narrative within art began at the turn of the $20^{\text {th }}$ century, to increase viewer's involvement in the story. Technology has created new formats that are ideally suited for nonlinear narrative. The same story can be told using linear and nonlinear narrative, but its structure needs to be adapted to each format. 
La evolución de la tecnología ofrece un formato donde la tradicional narración lineal apenas explota las posibilidades de este nuevo medio, donde el usuario lleva las riendas de la narración que se le presenta (sea esta del tipo que sea: un juego, una presentación empresarial, un mensaje publicitario, una página web, una experiencia artística, etc.), la narrativa no lineal es el sistema narrativo por excelencia.

En la narrativa no lineal y en la narrativa lineal la historia puede ser la misma. Lo que varía es la estructura en que se plantea la narración.

\section{Introducción}

A lo largo de la historia, la humanidad ha creado diferentes maneras para poderse comunicar y expresar. En sus orígenes fueron las imágenes y la lengua oral los vehículos de comunicación, todo ello antes de que se estableciera el código alfabético. Estos vehículos permitieron la transmisión de los relatos de generación en generación, manteniéndose viva la memoria colectiva.

En los dos últimos siglos, ha surgido un despliegue de conocimientos científico-tecnológicos. En primer lugar la imprenta, permitió que el siglo XIX fuese eminentemente narrativo expandiendo los saberes hacia todos los lugares posibles.

En segundo lugar ,en el siglo XX antes de la llegada de la digitalización a mediados del mismo, los autores literarios buscaron los modos de romper las limitaciones que imponía la tradición heredada del siglo XIX a su labor creativa sustituyendo el concepto de único autor, al multiplicar las perspectivas, rompiendo la sucesión cronológica del discurso... al tiempo que se proponían un reto para distanciarse del esquema secuencial propio de los discursos narrativos (introducción, desarrollo y desenlace). De tal forma que la lógica discursiva de los textos digitales rompía la secuencia tradicional (lineal), donde la información está interconectada y no existe una jerarquía en sus relaciones.

Por todo ello la tecnología nos retrotrae de esta forma a los inicios de la narrativa donde el relato se contaba de viva voz ante una audiencia motivada y motivadora de los cambios que se podían introducir en la historia contada. 


\section{Objetivos}

Con esta perspectiva nuestro objeto de estudio es presentar la evolución que ha seguido la narración desde los primeros relatos escritos hasta nuestros días. En primer lugar definiremos cuales son las características de la narración y como la linealidad se ha impuesto en la forma de narrar; en segundo lugar definiremos las principales características de la interactividad, a continuación haremos un breve repaso a las distintas propuestas que se han llevado a través de los tiempos para la ruptura de esa linealidad; para finalizar citando algunos ejemplos de narración interactiva que podemos encontrar en la actualidad y donde podemos encontrar semejanza con los productos de entretenimiento interactivo.

\section{Metodología}

El desarrollo metodológico del trabajo se ha realizado, principalmente, a través de la recopilación de los datos y conclusiones obtenidas de los diversos estudios que analizan tanto la narrativa como la interactividad. Así como del estudio de obras lineales y no lineales. Una vez analizados dichos artículos y obras hemos establecido los criterios que nos permiten llegar a las conclusiones que mostraremos en este artículo.

\section{Base de la Comunicación Narrativa}

El Paradigma narrativo según (Fisher, 1989), hace referencia a toda "comunicación con sentido" que refuerza la experiencia viendo esta comunicación en forma de una historia.

La narrativa: Se compone de estructura de significado en una secuencia ordenada de sucesos; aceptada por la cultura como válida puesto que la propia cultura facilita su validación; nos per- mite interpretar, estructurar y organizar la vida cotidiana.

Autores como García Jiménez, (García Jimenez, 1994)proponen distintos modelos asociados a la narrativa; modelo comunicacional; modelo semiológico; modelo actancial y modelo pragmático. En nuestro caso vamos a centrarnos en el modelo comunicacional. 
Este modelo considera la narrativa como un tipo particular del proceso narrativo. Donde el narrador es quien genera el acto comunicativo.

De esta forma el autor cede al narrador su voz, para que éste pueda comenzar a contar aquello que "ve" en el interior de esa ficción desarrollándose el proceso de la creación de la historia.

Básicamente, narrar implica que los hechos referidos estén relacionados, encadenados, y que se vayan sucediendo de forma más o menos lógica. Más concretamente: lo fundamental es que la sucesión de los hechos venga determinada por un principio de causalidad, esto es, que todo lo narrado tenga un 'antes' del que provenga y un 'después' al que se dirija.

\subsection{Que es una narración}

Hemos definido que la narración presenta lingüística o visualmente una sucesión de hechos que se producen a lo largo de un tiempo determinado y que, normalmente, da como resultado la transformación de la situación inicial.

Aunque este criterio puede aplicarse a diferentes situaciones comunicativas, en el ámbito de la comunicación literaria nos encontramos los siguientes géneros narrativos: Narración de hechos ficticios: novela, relato corto, epopeya, fábula; Narración de hechos no ficticios: crónicas de viajes, ensayos, biografías...

\subsection{Elementos de la narración}

Para construir una narración, los elementos de los que debe constar son, como mínimo, lo que se denomina un 'actor' (o 'personaje'), que es aquel que experimenta los sucesos o hechos referidos en ella. Este personaje puede o no, ser también narrador de la historia. $\mathrm{Al}$ ser una narración un encadenamiento de sucesos, las relaciones que se dan son de naturaleza causal y temporal: es decir, un hecho lleva a otro, por lo tanto, existe un fluir temporal que está sujeto a un orden dentro de una estructura

\subsubsection{Estructura argumental}

La estructura básica de una narración está compuesta por los siguientes hitos:

1. Introducción o planteamiento: Es la parte inicial de la historia, donde se presentan todos los personajes y sus propósitos. Pero fundamentalmente, donde se presenta la normalidad de la historia. Lo que se presenta en la introducción es lo que se quiebra $o$ altera en el nudo. La introducción 
sienta las bases para que el nudo tenga sentido.

2. Desarrollo o nudo: Es la parte donde se presenta el conflicto o el problema de la historia, toma forma y suceden los hechos más importantes. El nudo surge a partir de una alteración de lo planteado en la introducción.

3. Desenlace o final: Parte donde se suele dar el clímax, la solución a la historia y finaliza la narración. Incluso en los textos con final abierto, hay un desenlace. Puede terminar en un final feliz o no.

\subsubsection{Personajes}

Los personajes pueden ser de dos tipos planos o redondos. Denominamos personajes planos, a aquellos que han sido creados a partir de una idea, cualidad o defecto, pero no evolucionan a lo largo de la narración, es decir, no cambian o varían a lo largo de la historia. El lector ya los conoce y sabe cómo actuaran, por ello no pueden sorprenderlo. Por otra parte los personajes redondos, se definen por su profundidad psicológica ya que en el transcurso de la narración muestran las múltiples caras de su ser. El lector no los conoce de antemano, por lo que no sabe cómo actuarán. Evolucionan, cambian; pudiendo sorprender al lector con su comportamiento.

\subsubsection{Ritmo}

El narrador tiene también la posibilidad de contar la historia deteniéndose más o menos en los acontecimientos. Esta forma de narrar puede provocar sensaciones de rapidez o lentitud. En este caso la sensación viene producida por el uso de dos tipos recursos narrativos: la descripción (el tiempo se detiene) y la digresión autoral (comentarios del narrador). Por su parte, la sensación de rapidez proviene del uso del resumen (contar en pocas líneas lo que sucede en mucho tiempo) y la elipsis (eliminar fragmentos de la historia). Como forma intermedia, estaría el diálogo, al reproducir las palabras de los personajes, con lo que el tiempo narrativo se ajusta al tiempo real: su lectura dura lo que en teoría duraría ese diálogo en la realidad.

El narrador, dispone de dos maneras o estilos de reproducir la voz de los personajes de la historia: el estilo directo y el estilo indirecto.El primeroes el que se manifiesta cuando la voz de los personajes se reproduce de forma literal, esto es, cuando sus palabras o pensamientos se reproducen tal cual fueron dichas o pensadas, sin cambiar, añadir o quitar nada (directamente).

El segundo es el que utiliza el narrador cuando con sus propias palabras nos reproducen la voz de los personajes, esto es, cuando, de una manera u otra, 
nos resume sus palabras o pensamientos. El estilo indirecto implica, por un lado, la existencia de una selección de la información por parte del narrador (sólo reproducirá lo que a él le parezca conveniente) y, por otro, la falta de los matices emocionales y expresivos del personaje.

\subsubsection{Orden}

Es el narrador el que decide en qué orden y con qué ritmo se va a narrar la historia. Una de las primeras características que nos encontramos en la mayoría de los discursos narrativos es la cantidad de discordancias entre el orden de sucesión en la historia y orden de sucesión en el relato. En este caso es importante constatar que la linealidad del lenguaje obliga a un orden sucesivo para hechos que quizá son simultáneos y no lineales.

Por ello los mecanismos más utilizados por el narrador son; el denominado retrospección; flash back en las narraciones audiovisuales ('mirada hacia atrás'). A través de este se comienza a contar una historia y, en un determinado momento, se detiene la narración para contar cosas que ocurrieron en el pasado. Otro mecanismo menos utilizado sería el contrario, la prospección, esto es, el adelantar acontecimientos del futuro; flash forward en las narraciones audiovisuales.

\section{Narrativa Lineal vs. Narrativa no lineal}

La llegada de las tecnologías digitales han promovido la creación de obras que rompan la trama narrativa básica, convirtiéndose la discontinuidad en la característica básica del discurso propio de la red. Otro aspecto importante de la digitalización es intentar sustituir el papel eliminando los obstáculos que este soporte lleva asociado.

Nacen de esta forma obras que se plantean suprimir la linealidad publicadas en papel, especialmente durante la segunda mitad del siglo XX, de entre ellas cabría destacar la obra de Borges: "El jardín de los senderos que se bifurcan".

La premisa básica de esta obras es comenzar a trabajar con la ruptura de la linealidad. Intentando romper el paradigma narrativo, en el que los papeles del lector, el narrador, los personajes, el tiempo, etc. estaban plenamente establecidos.

Para que esta circunstancia se produjese era necesaria la aplicación de la interactividad. 


\subsection{La interactividad}

La interactividad es parte fundamental de nuestra vida, ya que es la forma en la que nos relacionamos con otros individuos.

La definición que nos proporciona Sheizaf Rafaeli como "una expresión extensiva que en una serie de intercambios comunicacionales implicaque el último mensaje se relaciona con mensajes anteriores a su vez relativos a otros previos" (McMillan, 2002).
Esto significa que aplicar la interactividad a obras lineales implica que se debe ver un cambio en la forma de acceder a la información; y también en la forma de crearla.

Los sistemas interactivos favorecen la comunicación bidireccional. Permiten la interconexión e integración del conocimiento, creando el efecto multiplicador, desarrollando procesos participativos donde la obra abierta en su construcción se convierte en una experiencia creando la información vivida.

\section{Narración hipertextual}

Aplicar la interactividad a obras lineales significa olvidarse de establecer una voz y visión dominante y acercarse al perspectivismo característica que encaja con la postmodernidad.

La narrativa hipertextual requiere de un lector activo, puesto que los roles de emisor y receptor pueden ser intercambiables, los contenidos pueden ser abiertos, dependientes de las elecciones del usuario y no hay una sola estructura central. En resumen, la propuesta es abandonar los actuales sistemas conceptuales basados en nociones como centro, margen, jerarquía y secuencialidad y sustituirlos por la multilinealidad, nodos, nexos y redes.
Nos encontramos con diferentes tipos de obras hipertextuales.

En primer lugar podemos hablar de Hiperficción constructiva o Escritura colaborativa: en esta, el lector puede modificar la historia, mientras que la hiperficción constructiva se basa en el trabajo colaborativo de varios autores (autoría compartida). También contamos con la hiperficción explorativa que tiene un solo autor, aunque da libertad al lector para tomar decisiones sobre sus trayectos de lectura, eligiendo qué nexos establecer en cada momento. Dentro de esta tipología encontramos un subtipo especial: la narrativa hipermedia, es decir, aquélla en la que además de texto y enlaces se incluye 
otro tipo de elementos multimedia, como el sonido, la imagen, la imagen en movimiento, etc.

Los modelos más recientes de novela hipermedia, como Golpe de gracia (Rodríguez, 2006), se acercan mucho al mundo de los juegos de ordenador, hasta el punto de que cabe preguntarse si no son realidades similares.

\subsection{Hiperficción constructiva}

La hiperficción constructiva consiste en el trabajo colaborativo de varios autores.

Uno de los antecedentes inmediatos de este tipo de experiencia son los juegos de rol, que desde los años 70 ofrecen un tipo de entretenimiento creativo con postulados muy parecidos a la liberación que propugnan los entusiastas del hipertexto. La hiperficción constructiva de este tipo era un ejemplo de autoría compartida cuya intención era más lúdica que estética, a pesar de que al realizarse por escrito permite superar la improvisación y poca elaboración de las intervenciones personales en una partida de rol.

Los antecedentes de la hiperficción constructivo podemos encontrarlos en el siglo de Oro Español y más recientemente con la llegada de las vanguardias, el surrealismo.
Tanto Lope de Vega, Cervantes, y Góngora que tuvieron escuelas y seguidores. El caso de Lope es especialmente llamativo ya que fue quien creó el teatro clásico español del Siglo de Oro con una novedosa fórmula dramática, dondemezclaba lo trágico y lo cómico, donde rompía las tres unidades que propugnaba la escuela de poética italiana (Ludovico Castelvetro, Francesco Robortello) fundada en la Poética y la Retórica de Aristóteles: unidad de acción (que se cuente una sola historia), unidad de tiempo (en 24 horas o un poco más) y de lugar (que transcurra en un solo lugar o en sitios aledaños).

Apollinaire, en el programa de mano que escribió para el musical Parade (mayo de 1917) acuña el término surrealista, pues considera que los autores han conseguido:

...una alianza entre la pintura y la danza, entre las artes plásticas y las miméticas, que es el heraldo de un arte más amplio aún por venir. (...) Esta nueva alianza (...) ha dado lugar, en Parade a una especie de surrealismo, que considero el punto de partida para toda una serie de manifestaciones del Espíritu Nuevo que se está haciendo sentir hoy y que sin duda atraerá a nuestras mejores mentes. Podemos esperar que provoque cambios profundos en 
nuestras artes y costumbres a través de la alegría universal, pues es sencillamente natural, después de todo, que éstas lleven el mismo paso que el progreso científico e industrial.

Los surrealistas señalaron como antecedentes a varios pensadores y artistas, como el pensador presocrático Heráclito, el Marqués de Sade y Charles Fourier, entre otros. En la pintura, el precedente más notable es Hieronymus Bosch "el Bosco", que en los siglos XV y XVI creó obras como "El jardín de las delicias" o "El carro de heno". El surrealismo retoma estos elementos $\mathrm{y}$ ofrece una formulación sistemática de los mismos.

Ya desde finales del siglo XX Internet ha ofrecido la posibilidad de crear obras de forma conjunta, aunque los resultados en muchos casos han sido obras lineales. En la mayoría de estos casos, sigue habiendo una voz autoral que decide.

Recientemente, se han desarrollado proyectos que intentan superar esta limitación: como Relátame (Morala \& Hidalgo) que se define como "un sitio donde crear relatos colaborativos. Es decir, escritos por diferentes usuarios. Aquí tu puedes empezar tu propio relato o continuar uno ya existente.

No solo puedes contar historias, también puedes comentarlas, votarlas, crear finales alternativos, ponerles voz,..."

O la novela El Libro flotante de Caytran Dolphin (Tisselli, 2006) que toma la novela de Leonardo Valencia y la convierte en un hiperrelato en el que pueden colaborar los lectoautores.

Otro ejemplo lo encontramos en el ámbito académico, la universidad de Deusto desarrolló un proyecto de escritura colaborativa empleando el formato wiki, denominado wiki novela que se inició en abril de 2004 y finalizado en junio del mismo año. A través de este proyecto se intento de crear una obra colectiva, multilingüe e hipertextual. (Deusto, 2004)

En resumen la producción textual colaborativa es una modalidad de trabajo que se basa en la actitud altruista de los colaboradores con el fin de contribuir a incrementar y mejorar el conocimiento.

\section{2 Hiperficción} Explorativa, Narrativa hipermedia y videojuegos

En párrafos anteriores definíamos la hiperficción explorativa como la obra escrita por un solo autor, pero que permite al lector tomar sus propias decisiones en la continuidad del relato. Este tipo de obra exige una actividad constante que de alguna manera acerca 
los papeles autor-lector aunque no los llega a confundir, ya que a pesar de la capacidad de elección del lector, hay un autor que no pierde el control de la obra ya que es el que ha creado y los ha pensado anteriormente. Por el ello el lector no participa en la obra solo disfruta de ella.

Algunas de las estrategias utilizadas en la creación de los relatos hipermedia son:

1. La Secuencia: La narración tradicional se estructura de acuerdo a una secuencia cronológica. Ese sería el orden secuencial de los films, cómics... que siguen una secuencia cercana a la propuesta en los cuentos tradicionales. Los discursos hipertextuales, sin embargo, se estructuran con una secuencia narrativa anacrónica en la que la historia no responde a un orden sucesivo, ni tampoco coincide con el tiempo del discurso. Este tipo de discursos son propios de los videojuegos y los videoclips.

2. El Autor: no aparece con claridad, ya que se encuentra oculto tras las elecciones que lleva a cabo el lector, que puede llegar a confundirse con la autoría de los relatos.

3. El Espacio Lector: el lector participa en la trama a partir de su propia inmersión en la toma de decisiones, acto que le permite configurar su propia historia. Es él quien le confiere unidad y sentido al relato que propone el programa. La interactividad permiteque el usuario crea que pueda decidir sobre la máquina aunque en realidad está seleccionando sobre reglas ya previstas en el propio diseño. De esta forma el jugador se siente incluido en la trama porque el programa le permite desempeñar un rol, lo que produce una fuerte identificación.

La aplicación de estas estrategias dan como resultado la creación de narraciones interactivas. Concepto que se asocia erróneamente siempre con videojuegos, pues aunque todos los videojuegos son interactivos no en todos encontramos una narración. Tomemos como ejemplo un juego de simulación ${ }^{\text {ii }}$-Flight Simulator ${ }^{\text {iii }}$-o un mundo virtual $^{\text {iv }}$-Habbo- donde aunque podemos encontrar personajes con historia, no encontramos una historia en si misma.

En palabras de Marc Laidlaw'debemos distinguir entre historias o contar historias, pues de esto segundo trata la narración interactiva. Hay juegos en los que la historia se nos cuenta al principio y después nos sumergimos en juego. Un ejemplo lo encontramos en el juego de rol multijugador masivo en línea -World of Warcraft ${ }^{\mathrm{vi}}$-, en el que al inicio del mismo se nos cuenta 
la historia que da origen al juego y las dos facciones que se enfrentan - la Alianza y la Horda- pero que no es necesario seguir para poder jugar. Pero una buena narración te lleva a lo largo del ritmo, la trama, el detalle y la revelación(Yang, 1998). Un ejemplo lo encontramos en - Silent Hill II ${ }^{\text {vii }}$ - donde a través de la trama nos vamos sumergiendo en la historia tomando parte en ella.

Los elementos básicos que se utilizan en la construcción de una Narración Interactiva son; el rol del jugador, el desarrollo del personaje, la estructura, el planteamiento, los puntos de conflicto, la trama y el tiempo.

A la hora de crear el rol del jugador se puede dar la opción del jugador como protagonista, como determinante de las características del personaje, ó como creador de las relaciones entre personaje, compañeros y entorno.

La caracterización de un personaje interactivo es mas complejo que en una obra lineal, pues se debe definir el grado de control del jugador sobre el personaje y además se deben crear entre otros elementos diferentes puntos de vista para poder jugar. Lo que nos puede llevar a encarnar diferentes personajes a lo largo del transcurso del juego como en _Heavy Rain- ${ }^{\text {vii }}$

La estructura de la narración interactiva se refiere a la navegación y arqui- tectura. De tal forma que podemos crear una estructura lineal, lineal con ejemplos de ramificaciones, jerárquica, historias paralelas o mundos relacionados.

En cuanto al planteamiento en una obra interactiva, este aspecto se refiere a la forma en que se va a presentar el proyecto al jugador. Como se va a introducir el personaje, la historia, el ambiente. En la fase de diseño es cuando debemos tomar las decisiones sobre la creación escenas introductorias, que tipos de dispositivos que nos permitan acceder a la información necesario en cada momento usaremos y también si es necesario debido a la complejidad del proyecto desarrollar alguna fase en el que se realice una demostración de cómo funcionará el programa.

La trama y el tiempo en un proyecto interactivo es como crear una serie compuesta de muchos capítulos como encontramos en el videojuego- The Legend of Zelda: Twilight Princess- ${ }^{\text {ix }}$

En resumen crear una narración interactiva no es sencillo, ya que es necesario tener la capacidad de contar una historia, el análisis para la creación de un programa informático, la creatividad para la definición de un diseño visual y todo ello coordinado con una planificación que permite que diferentes perfiles de profesionales puedan 
opciones.

\section{Conclusiones}

Aunque desde los inicios de la comunicación se ha intentado que el lector pueda tomar parte en la obra formando parte de ella, desde el teatro del siglo de oro, a la llegada de los videojuegos pasando por la creación de los relatos surrealistas con sus cadáveres. Ha sido el desarrollo tecnológico y más concretamente la digitalización la que ha permitido la creación de obras que replican la forma básica de comunicar. La bidireccionalidad que proporciona la interactividad es la que permite que hayamos pasado de contar historias a crear experiencias. Que el lector / audiencia / publico, se convierta en usuario /jugador. Pero no en autor, ya que la autoría excepto en los proyectos de hiperficción colaborativa dependerá de un autor, que creará las líneas básicas sobre las cuales el usuario podrá tomar las decisiones que le permitan avanzar en la historia, o que posibiliten que pueda vivir más de una experiencia con los mismos personajes.

Este tipo de narrativa proporcionará nuevas experiencias a los usuarios, su avance y su desarrollo posibilitará que se diseñen diferentes productos que además de entretener, el lector convertido en usuario viva experiencias nuevas en mundos fantásticos a través de los cuales pueda aprender, informar y crear.

\section{Referencias}

Yang, J. (1998, Septiembre 25). gamingnexus. Retrieved Diciembre 30, 2011, from www.gamingnexus.com: http://www.gamingnexus.com/Article/ValveSofware-Interview-Marcc-

Laidlaw/Page1/Item801.aspx

Deusto, U. d. (2004, Abril 24). Wikinovela. (F. d. Letras, Producer) Retrieved Diciembre 29, 2011, from Wikinovela: http://www.wikinovela.org

Fisher, W. (1989). Human Communication as Narration: Toward a Philosophy of Reason, Value, and Action. Columbia: University of South Carolina Press.
García Jimenez, J. (1994). Narrativa audiovisual. Madrid: Cátedra.

Huizinga, J. (1987). Homo Ludens. Madrid: Alianza.

Nelson, T. A file structure for the complex, the changing and the indeterminate. ACM Proceedings of the 20th National Conference (pp. 84-100). ACM.

McMillan, S. (2002). Exploring Models of Interactivity from Multiple Research Traditions: Users, Documents and Systems. In L. Lievrouw, \& S. Livinstong, Handbook of Media (pp. 162-182). London: Sage. 
Morala, A., \& Hidalgo, I. A. (n.d.). Retrieved Diciembre 29, 2011, from Relatame: http://www.relatame.com

Rodríguez, J. A. (2006). Golpe de Gracia. Retrieved Agosto 29, 2011, from Pontificia
Universidad Javeriana, Bogotá:

http://www.javeriana.edu.co/golpedegracia/

Tisselli, E. (2006). Libro flotante de Caytran Dolphin. Retrieved Diciembre 29, 2011, from http://www.libroflotante.net

Cita de este artículo

Legeren Lago, B . (2012) De Homero a Laidlaw. La digitaliza-

ción recupera la participación en la obra narrativa. Icono14

10(2), 29-42, doi: $\underline{10.7195 / \text { ri14.v10i2.153 }}$

\section{NOTAS}

${ }^{\text {i }}$ Sheizaf Rafaeli. Director del Center for the Study of the Information Society y Director de la Graduate School of Management, en la Universidad de Haifa, Israel.

${ }^{i i}$ Los videojuegos de simulación son videojuegos que intentan recrear situaciones de la vida real. Los videojuegos de simulación reproducen sensaciones que en realidad no están sucediendo. Pretenden reproducir tanto las sensaciones físicas (velocidad, aceleración, percepción del entorno) y una de sus funciones es dar una experiencia real

iii Se denomina así a la serie de simuladores de vuelo desarrollada por Microsoft para el sistema Microsoft Windows .

${ }^{\text {iv }}$ Un mundo virtual es un tipo de comunidad virtual en línea que simula un mundo o entorno artificial inspirado o no en la realidad, en el cual los usuarios pueden interactuar entre sí a través de personajes o avatares, y usar objetos o bienes virtuales

${ }^{\mathrm{v}}$ Marc Laidlaw(nació 1960) es un escritor Americano de ciencia ficción y tambien el diseñador de videojuegos con la empresa Valve. Conocido por sus novelas Dad's Nuke y The 37th Mandalay por trabajar en la serie de videojuegos Half-Life.

${ }^{v i}$ World of Warcraft. Es comúnmente conocido como WoW, es un videojuego de rol multijugador masivo en línea(creado y dirigido por John Carrison, Roqueford Smith y Luzbelt Keys) Actualmente tiene alrededor de 12 millones de suscriptores.

${ }^{\text {vii }}$ Silent Hill II. Es un videojuego de survival horror desarrollado por Team Silent y publicado por Konami en 2001 para la Sony PlayStation 2. Aunque es una secuela de la primero, no sigue los eventos del primero.

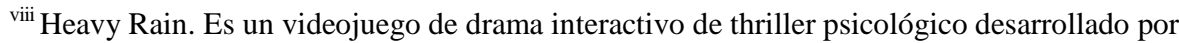
Quantic Dream y distribuido por Sony Computer Entertainment exclusivamente para PlayStation 3. Heavy Rain es una aventura gráfica, pero también es factible llamarlo película interactiva, como lo califican sus creadores, donde el jugador maneja a los diferentes personajes pudiendo decidir cómo avanza la trama, decidir los giros argumentales de la misma e incluso el destino de sus protagonistas. 
ix The Legend of Zelda: Twilight Princess. «La leyenda de Zelda: la princesa del crepúsculo») es un videojuego de acción-aventura de 2006 desarrollado por la filial EAD y distribuido por Nintendo. Twilight Princess contiene dos mundos: Hyrule y el Reino del Crepúsculo. Divididos en nueve niveles de acción, denominadas en el juego mazmorras. 